\title{
Farmers' Knowledge, Attitude and Practices on Pesticide Safety: A Case Study of Vegetable Farmers in Mount-Bamboutos Agricultural Area, Cameroon
}

\author{
Sonchieu Jean ${ }^{1 *}$ (1), Fointama Emmanuel ${ }^{2}$, Akono Nantia Edouard ${ }^{3}$, Serri Brownlinda ${ }^{1}$ \\ ${ }^{1}$ Department of Social Economy and Family Management, Higher Technical Teacher Training College, \\ The University of Bamenda, Bamenda, Cameroon \\ ${ }^{2}$ Department of Food Science and Technology, College of Technology, University of Bamenda, Bamenda, \\ Cameroon/Service of Nursing and Dietetics, Bambili Health Center, Bamenda, Cameroon \\ ${ }^{3}$ Department of Biochemistry, Faculty of Science, University of Bamenda, Bamenda, Cameroon \\ Email: *jsonchieu@yahoo.fr, efointama@yahoo.com, edouardakono@gmail.com, sefmh919@gmail.com
}

How to cite this paper: Jean, S., Emmanuel, F., Edouard, A.N. and Brownlinda, S. (2019) Farmers' Knowledge, Attitude and Practices on Pesticide Safety: A Case Study of Vegetable Farmers in Mount-Bamboutos Agricultural Area, Cameroon. Agricultural Sciences, 10, 1039-1055.

https://doi.org/10.4236/as.2019.108079

Received: June 20, 2019

Accepted: August 10, 2019

Published: August 13, 2019

Copyright $\odot 2019$ by author(s) and Scientific Research Publishing Inc. This work is licensed under the Creative Commons Attribution International License (CC BY 4.0).

http://creativecommons.org/licenses/by/4.0/

\begin{abstract}
Pesticides are commonly used in Cameroon for farming purposes, especially in the Mount-Bamboutos agricultural area. This study aimed to evaluate the basic knowledge, attitude and practices among pesticide users in the said area in view of assessing the level of safety and health risks due to pesticide exposures or contaminations. Data was collected through survey study on pesticide knowledge, marketing, attitude and practices on spraying skills, toxicity, health issues, management, first aids and literacy of operators. Results revealed that both male and female were involved in agricultural practices with their ages varying from 21 to 60 years. The farmers were generally of low education level. The main crops cultivated are leafy and fruit vegetables, tubers, cereals, roots and fruits. Half the participants purchased pesticides from the neighborhood. Ethylene bis-dithiocarbamate (EBDC) and cypermethrin were the two main pesticides used by the farmers. Seventy percent $(70 \%)$ of pesticide containers were thrown in the environment after usage. A certain portion of the sprayers (12\%) did not know the existence of residues after application while, as routes of penetration up to $42 \%$ pointed the mouth as the route for pesticides into human body. Very few respondents (3\%) identified the intervention hospital in case of pesticide poisoning. This study highlights poor knowledge on the use and handling of pesticides in Mount-Bamboutos agricultural area. Sensitization campaigns should be put in place, involving different stakeholders, to train farmers in pesticide risks and management.
\end{abstract}




\section{Keywords}

Pest Management, Ability, Awareness, Pesticides, Handling

\section{Introduction}

The use of pesticides in farming and other domains is subjected to applicator's perception that may be trained or not for the purpose. Farmer knowledge on pesticide use, aptitude to apply the acquired knowledge and the capacity to practice the said aptitude are determinant for the quality and safety of the produce. The amount of pesticide residues found in the end products will depend on the management of formulations during cropping. In this sense, consequences such as pesticide poisonings and environmental contamination are often blamed on pesticide users like farmers and farm workers. This is generally termed misuse that assumes that the farmers, farm workers, and others have access to the relevant risk information, can read the information and comprehend to a level where they can apply this information; protect themselves, consumers and ecosystems [1]. Pesticide misuse is very common in developing countries which constitute the most affected zone for pesticide poisonings. The method of spraying pesticides, materials used during spraying, the spraying period, integrated pest management, the spraying parameters such doses, pre-harvest-period and spraying techniques are generally viewed as anthropological parameters able to harm human's health [2] [3].

The harmful effects of pesticide on humans have been shown as one of the main cause of many diseases and death in the world [4]. Pesticides can inhibit acetylcholinesterase leading to the accumulation of excess acetylcholine in synapses, which in turn result in over-stimulation of the cholinergic nerve terminals. This will hamper the normal functioning of the whole nervous systems [5]. As result, the acute health effects including tremor, paralysis, confusion, convulsion, coma, gastro-intestinal distress and death will appear [6] [7]. Continuous exposure to some particular insecticides may lead to chronic health effects such as developmental and neurobehavioral anomalies, cancer, gene mutation [8] [9]. Generally, exposure to pesticides occurs mainly through the dermal, inhalation and oral routes [10].

In Cameroon, the Mount Bamboutos area constitutes one of the agricultural zones where production of vegetables is considerable. In this zone, the agricultural system remains traditionally based on combined production systems destined for family consumption and marketing. However, with the reduction of the arable land together with increasing demand of agricultural products and increase of pest attacks, the Cameroon agriculture system is increasingly using pesticides to enhance crop yield [11] [12]. Studies have noted pesticide mishandlings and misuses in some Cameroon localities with serious health consequences on practitioners [12] [13] [14]. Though the mount Bamboutos area 
represents an important zone of pesticide applications, no study has been designed to investigate the actual problem related to farmers' attitude towards pesticides despite new farming systems reported. They include intensification of arable areas, intense local and mechanical irrigation systems, severe application of farm inputs, and confinement of ruminants. Production is both permanent and seasonal. According to survey carried out by Gountié et al. [15], the most produced crops are carrot, irish potatoes, cabbage, leeks and onion. The growth of maize, beans and potatoes is limited because of the high slope gradient, acidic $\mathrm{pH}$, high rainfall and wetness in some foots lopes [16]. The poor land use including land cover depletion, intensification and extension of agricultural activities has negatively impacted plant species diversity and are aggravating the susceptibility of the landscape to erosion and mass movements [17]. According to the study conducted by Pouokam et al. [18], demographic data are similar to those of other high lands of west Cameroon.

These authors reported that the level of education is very low since the majority are holder of FSLC and many of them were illiterate but with more than twenty years of experience. [12] Reported the same view in Santa and Foumbot areas where pesticide misuse is frequently observed. They also mentioned the lack of technical assistance of agricultural qualified technicians from the Ministry of Agriculture and Rural Development. Few of them have undergone formal training and would not be able to understand information carried on labels. Even though information is labeled, the local environmental conditions will not permit a real degradation before consumption time. Nevertheless, education of pesticide users has been given by pesticide sellers, relatives, colleagues and through seminars [19] [20]. It is all known that the ability to read will improve the knowledge and the desire to apply the said knowledge for the individual and consumers good. Many diseases have been reported among farmers in similar cropping because of unawareness of farmers and workers who dress poorly and ignored the toxicity of the chemical that they use [21] [22].

Many cases of intoxications and related pesticide signs and symptoms have been reported amongst farmers of Mount-Bamboutos agricultural area. Need arises to evaluate their knowledge, attitude and practices in the use of pesticides. Many studies have been conducted on practices of pesticide uses and the following questions were asked: do pesticide users (small-scale farmers in Mount-Bamboutos) have enough knowledge on pesticide application? If yes which attitude do they adopt for appropriate spraying and how do they put into practice the acquired knowledge? This study aimed to evaluate the basic knowledge, attitude and practices among pesticide users in the mount Bamboutos agricultural area by assessing the farmer awareness, level of safety and health consequences due to pesticide exposures or contaminations.

\section{Materials and Methods}

\subsection{Presentation of the Study Area}

The Bamboutos Mountain is made up of a volcanic complex. The group of 
Bamboutos mountains, which is the third largest massif in Cameroon fault line with an altitude of $2740 \mathrm{~m}$, is characterised at the summit by an eclipse like a collapsed Caldera and links to the north to mount Oku. It is located between latitudes $5^{\circ} 38^{\prime} \mathrm{N}$ and $5^{\circ} 43^{\prime} \mathrm{N}$ of the Equator and between longitudes $9^{\circ} 58^{\prime} \mathrm{E}$ and $10^{\circ} 06^{\prime} \mathrm{E}$ of the green-which meridian [15]. The Bamboutos mountains have a surface area of about $261 \mathrm{~km}^{2}$ comprising main villages that include M'Muock, Fosimondi, M’MuockLeteh, and Bamumbu, Magha, Atsualah, Nkongne, Marita, Banteng, Talung, Ekotoneh, Tekouh, Egumbo, Folepi, Bechati, Besali, Bangang and Nkong and is limited in the East by the Noun plain and in the West by the calderas. It is organized into low, moderate and high hills which are repeated in the landscape, separated by large and narrow valleys. Globally, natural vegetation consists of typical tropical species. The temperature varies between $17^{\circ} \mathrm{C}$ and $32^{\circ} \mathrm{C}$, with two seasons: rainy season, which runs from March to October, and the dry season from November to February [17]. Main activities carried out around this area are farming and animal rearing [23]. Figure 1 indicates the geographical location of the study area.

\subsection{Data Collection}

Data were collected using a questionnaire based on the following parameters: knowledge, attitude and practices on the following factors: spraying parameters, toxicity of pesticides, health issues, pesticide management, first aids, literacy of operators and pesticides marketing. The area was divided into four sectors and respondents were randomly selected by a set of 25 within each one four villages constituted as followed: Sector A: M’Muock, Fosimondi, M'MuockLeteh, and Bamumbu. Sector B: Magha, Atsualah, Nkongne, Marita, Banteng. Sector C: Talung, Ekotoneh, Tekouh, Egumbo. Sector D: Folepi, Bechati, Besali, Bangang and Nkong. The area of study was partitioned according to the number of farmers. Depending on the availability of the farmer to pay attention to field operators and their ability to read and write, questionnaires were filled in by the respondents themselves or with the help of a field operator. A total number of 130 questionnaires were distributed and 125 collected back among which 100 were valid.

\subsection{Statistical Analysis}

Data were analyzed using SPSS software, version 20 (SPSS Inc., Chicago, IL, USA). Descriptive results were expressed with frequencies and percentages. Because of the type of the study, various factors that included demographic factors, distribution of the population according to their perception on pesticide use were evaluated.

\section{Results and Discussion}

\subsection{Demographic Data}

Farmers involved in this study were classified in various groups of factors 


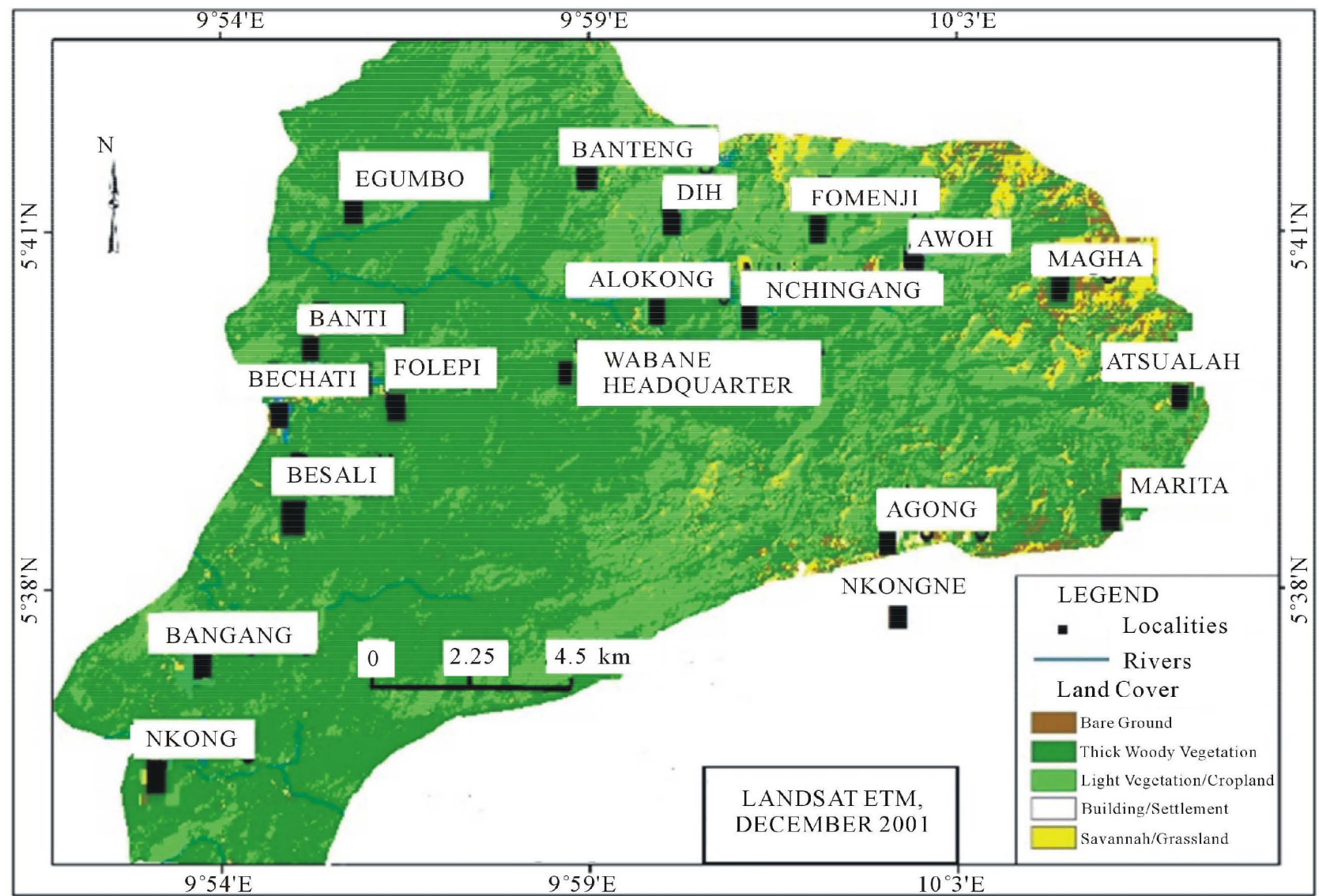

Figure 1. Satellite images of the Mount Bambouto Caldera of the western highlands of Cameroon. Source: Formeluh et al. (2018).

including sex, level of income, number of family members and level of education (Table 1).

In the Bamboutos Mountain area, there was slightly more male (58\%) than female involved in this study. Farmers were distributed in various income classes depending of the size of their farm and the number of workers they employ. More of them belong to the low middle class (57\%) while few (18\%) was for the middle-class income. The level of education varied from illiterate to graduate people. The majority (54\%) attended secondary school education with GCE/O level, only $10 \%$ were illiterate and seldom graduate people practice agricultural activity. Participants were aged from 21 to 60 years, with the majority (31\%) constituted of young people aged between 21 to 30 years old. Their family sizes varied from one to 12 persons, and the most represented class having less than four members (47\%).

\subsection{Types of Crops and Pesticides}

Table 2 presents the crops cultivated and type of pesticides used by farmers in mount Bamboutos agricultural area. The crops were essentially spices(green pepper, onion, pepper and leek), leafy vegetables (lettuce, cabbage, green beans, cauliflower) and fruit vegetables (tomato, garden egg), tubers (irish potato, sweet 
Table 1. Demographic data from farmers.

\begin{tabular}{|c|c|c|c|c|c|c|c|c|c|c|c|c|c|c|c|c|}
\hline \multirow{2}{*}{$\begin{array}{c}\text { Sex } \\
(N=100)\end{array}$} & \multicolumn{3}{|c|}{ Income } & \multicolumn{4}{|c|}{ Age (years) } & \multicolumn{5}{|c|}{ Level of education } & \multicolumn{4}{|c|}{ Family size } \\
\hline & Poor & LMC & MC & [21 - 30] & {$[31-40]$} & [41 - 50] & {$[51-60]$} & Ill. & PS & SS & UG & Gra. & Alone & $1-4$ & $5-8$ & $9-12$ \\
\hline Male & $15(60)$ & $27(57)$ & $16(57)$ & $19(50)$ & $10(48)$ & $19(76)$ & $10(63)$ & $6(60)$ & $5(55)$ & $32(59)$ & $12(52)$ & $3(75)$ & $10(67)$ & $26(55)$ & $22(59)$ & $0(0)$ \\
\hline Female & $10(40)$ & $20(43)$ & $12(43)$ & $19(50)$ & $11(52)$ & $6(24)$ & $6(37)$ & $4(40)$ & $4(45)$ & $22(41)$ & $11(48)$ & $1(25)$ & $5(33)$ & $21(45)$ & $15(41)$ & $1(100)$ \\
\hline Total & $25(25)$ & $57(57)$ & $18(18)$ & $38(38)$ & $21(21)$ & $25(25)$ & $16(16)$ & $10(10)$ & $9(9)$ & $54(54)$ & $23(23)$ & $4(4)$ & 15 (15) & $47(47)$ & 37 (37) & $1(1)$ \\
\hline
\end{tabular}

LMC = Low middle class; $\mathrm{MC}$ = middle class; Ill = Illiterate; PS = primary School; SS = Secondary School; UG = Undergraduate; Gra. = Graduate.

potato), cereals (corn), root (carrot) and fruit (watermelon). Two classes of pesticides fungicides and insecticides were used for cultivation. Herbicides are not frequently used. Pesticide active ingredients were essentially ethylene bis-dithiocarbamate (EBDC) (85\%) for fungicide and cypermetrhin for insecticide. Mancobex and macomax were the most used formulations (75\%).

\subsection{Health Issues Related to Pesticides}

Farmers in Mount-Bamboutos agricultural zone challenge many symptoms related to pesticide harm as shown in Table 3. At the same time, they express this issue as faced problem and their ignorance to be caused by pesticides that they apply daily. Their knowledge was evaluated on: symptoms, routes of penetration and action took after getting in contact with pesticides. Only $4 \%$ of respondents declared having no knowledge of symptoms related to pesticides intoxication. However, the majority recognized various symptoms due to exposure or to intoxication to pesticides; while some (9\%) do not have any idea about symptoms manifested by a victim of pesticide poisoning. The similar observations are given about routes of intoxication. The mouth is the most common route while intoxication through skin was less reported by the majority $(2 \%)$ and $14 \%$ do not have idea on how pesticides affect them. Most respondents said when the skin of a sprayer gets into contact with pesticides, this can just be cleaned with a piece of cloth, in most cases or wash with water (81\%). In very few cases, the poisoned person is taken to the hospital. Nevertheless, when an operator is intoxicated with pesticides, many actions can be taken as first aids: washing, giving charcoal, milk, vomiting and sending to hospital. Globally, the population ignored the health risks linked to pesticides manipulation.

\subsection{Pesticides Management}

Pesticide users manage containers in various ways as shown in Table 4. Their knowledge of the existence of pesticides in food after spraying is presented in the same Table 4.

As seen in Table 4, 70\% of investigated farmers throw empty containers in most cases in barren land, running water (river or stream) and in garbage. On 


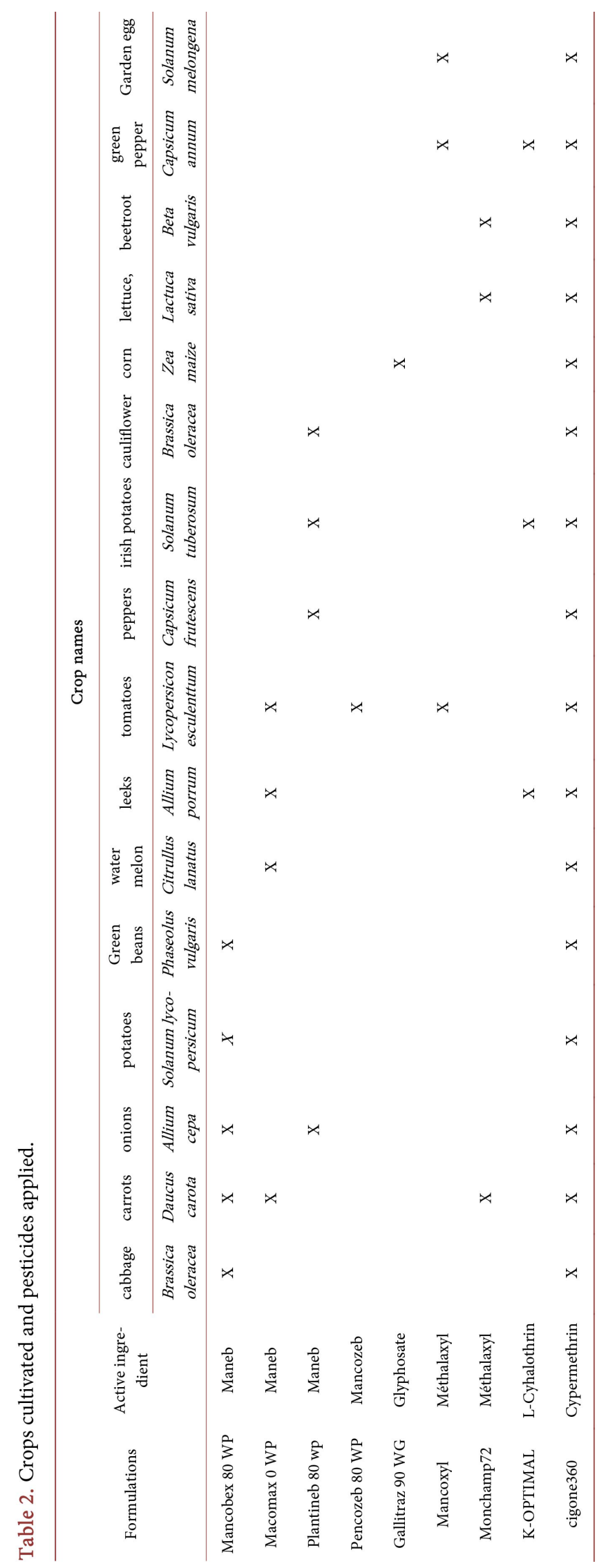


Table 3. Knowledge of farmers on used containers and residues of pesticide in food.

\begin{tabular}{lcc}
\hline Measured factor & Evaluated parameter & Frequency (\%) \\
\hline No response & $4(4)$ \\
Management of & Throwing in garbage & $34(34)$ \\
& Throwing in barren land/water source & $36(36)$ \\
& Burning & $7(7)$ \\
& Cleaning and reuse & $7(7)$ \\
& All of the above & $4(4)$ \\
& Other (burrying, selling) & $5(5)$ \\
\hline No idea & $3(3)$ \\
& No response & $4(4)$ \\
& Air & $10(10)$ \\
& Soil & $29(29)$ \\
Gxistence of residues & Ground water & $18(18)$ \\
& Fruits, seeds and leaves & $17(17)$ \\
All of the above & $14(14)$ \\
None of the above & $3(3)$ \\
No idea & $5(5)$ \\
\hline
\end{tabular}

Table 4. Awareness of farmers on the importance of label, storage, pre-harvest period and route of intoxication.

\begin{tabular}{|c|c|c|}
\hline Factors & Parameters & Frequency (\%) \\
\hline \multirow{3}{*}{$\begin{array}{l}\text { knowledge of storage of } \\
\text { pesticide }\end{array}$} & Blanc & $4(4)$ \\
\hline & Not aware & $69(5)$ \\
\hline & Aware & $27(27)$ \\
\hline \multirow{2}{*}{ Knowledge of reading labels } & Aware & $32(27)$ \\
\hline & Not aware & $68(68)$ \\
\hline \multirow{10}{*}{$\begin{array}{c}\text { Awareness on } \\
\text { pre-harvest period } \\
\text { Mode of transmission }\end{array}$} & Multiple answers & $4(4)$ \\
\hline & Awareness & $90(90)$ \\
\hline & No awareness & $6(6)$ \\
\hline & No response & $11(11)$ \\
\hline & Nose & $19(19)$ \\
\hline & Skin & $2(2)$ \\
\hline & Mouth & $42(42)$ \\
\hline & Eyes & $10(10)$ \\
\hline & All routes & $13(13)$ \\
\hline & No idea & $3(3)$ \\
\hline
\end{tabular}


the other hand, some clean and reuse the emptied containers as house utensils or burn. Some manage the pesticide packages according to their mood and can throw, burn, reuse, burry or sell to others for other purposes such as measurement instruments.

Their knowledge on the persistence of pesticides in edible part of crop and in the environment remains confusing. Most of them (57\%) know about the presence of pesticides in soil, air and ground water while $15 \%$ were completely ignorant of the persistence of pesticides wherever after spraying. Considering this poor knowledge, only $17 \%$ are aware that pesticides can remain inside fruit, seeds or leaves. The others asserted that pesticides will not penetrate and to a certain extent the fruit.

\subsection{Information on Pesticides}

Investigated farmers have given various responses and express their awareness and perception on different aspects of preventive methods to avoid intoxication and to increase the effectiveness of pesticides they use. Table 5 presents various elements that indicate their perception about the subject.

As seen in Table 5, most of them are aware of poisoning through mouth (47\%) but still ignorant about other routes of transmission such as skin, eyes or nose (31\%). However, $13 \%$ know that all the listed routes can be possible and lead to the harmful effects of pesticides in the human body. Some (14\%) do not have any idea or do not know about routes of contamination. Nevertheless, $90 \%$ are aware that they should not harvest foods before a certain time period, to avoid poisoning. But $10 \%$ remain confused about the pre-harvest period. Part of this information is generally given by manufacturers on the labels but only $32 \%$ are aware of the need to read the label in order to understand the usage mode. In addition, very few of them are aware on how to store pesticides. Twenty seven percent (27\%) affirmed having knowledge of storage precautions. Furthermore, the remaining $73 \%$ think that they can store their pesticides anywhere after purchasing and being using it on their one way.

\subsection{Assessment on the Attitude of Farmers towards Pesticide Uses}

To assess the attitude of farmers to apply the knowledge that they have, the following factors were measured: safety and direct effect of pesticides, and consequences of long term exposure. Table 6 presents various opinions of respondents.

Following information collected from farmers and presented in Table 6, 60\% declared to be aware that pesticides are not safe and should be manipulated with caution. But, $40 \%$ do not have any clear opinion as to the safety of these chemicals. Then, 63\% agree that pesticides have direct effect if they enter the body of consumers or of the sprayer. Some respondents recognize the fact that not all are poisonous while others have unclear answers. In the other hand, most of them 
Table 5. Perception on health issues.

\begin{tabular}{lcc}
\hline Factors & Parameter & Frequency (\%) \\
\hline Multiple actions & $9(9)$ \\
Fction after intoxication & Find out mode of contamination & $13(13)$ \\
& Take person to the hospital & $3(3)$ \\
All of the above & $36(36)$ \\
\hline $\begin{array}{c}\text { Action after skin } \\
\text { contamination }\end{array}$ & None of the above & $16(16)$ \\
No response & $11(11)$ \\
Clean with a cloth & $41(41)$ \\
Wash with soap and water & $40(40)$ \\
Make a call to the poison information center & $4(4)$ \\
Take the person to the nearest hospital & $4(4)$ \\
\hline Multiple symptoms stated & $10(10)$ \\
Hymptoms of intoxication & Headache & $7(7)$ \\
Cough/chest pain/cold/breathlessness & $48(48)$ \\
All of the above & $22(22)$ \\
None of the above & $4(4)$ \\
No idea & $9(9)$ \\
\hline
\end{tabular}

Table 6. Awareness of farmers on pesticide-related risks.

\begin{tabular}{ccc}
\hline Factors & Opinion & Frequency (\%) \\
\hline \multirow{2}{*}{ Safety of Pesticides } & Agree & $19(19)$ \\
& Disagree & $60(60)$ \\
& No opinion & $21(21)$ \\
\hline Immediate effect of pesticides & Agree & $10(10)$ \\
& Disagree & $(23) 63$ \\
& No opinion & $27(27)$ \\
\hline Exposure leads to immunity & Agree & $63(63)$ \\
& Disagree & $10(10)$ \\
& No opinion & $27(27)$ \\
\hline
\end{tabular}

(63\%) think that continuous exposure to pesticides will lead them to acquire some immunity to the pesticides they apply frequently. In the same light, few do not know whether exposure will lead to acquire immunity or not.

\subsection{Evaluation of Various Practices Conducted by Farmers in Applying Pesticides}

In terms of practicing, farmers presented different opinions on places where they 
buy chemicals, advices received, attire and personal hygiene. All the information collected is presented in Table 7 that indicates that farmers acquire pesticides from various places like licensed shops, neighborhoods, and other places. But many get them from neighborhood (50\%) because many retailers are found in the community. To buy pesticides from licensed shops remains a challenge for farmers since they have to go to main cities. Generally, advice on pesticides usage is gotten from sellers (59\%) but also from relatives and colleagues who counsel from their own experience. Information given by manufacturers is at time used by some of them but since they are of low educational level, they go to those who can reinforce their capacity with more explanation. Some farmers acknowledged that from time to time they use some attire either separately or together with others. The most used is the mouth and nose mask (52\%) compared to other accessories such as gloves, glasses, rain boots and full-sleeved shirts. However, some do not use any of them and expose their body to toxins. After spraying most of farmers interviewed do not take bath immediately as soon as the operation is ended while $37 \%$ take their bath as soon as they come back from the work. However, some do not bath on regular basis after spraying. They even carry out other activities such as carrying children, playing with kids, eating and smoking after using these chemicals prior to bathing.

\subsection{Discussion}

The data related to demography of the studied population is in accordance with that reported by other authors in Santa, Djutitsa and Foumbot farming areas. Similitudes are found in all aspects such as involvement of both sexes, the levels of education and ages) [13] [14] [17]. However, those authors did not consider the number of family members which is a great factor in man power and possibility of extending the knowledge and impacting the activity as mentioned by [24]. It is important to notice that the size of the family will influence the size of the farm.

Crops cultivated are the same found in other agricultural areas in the North-West Region like Santa, or in Foumbot except that cauliflowers and watermelon are added [13] [19]. On the other hand, pesticides used are very common as mentioned above. Fungicides which are all ethylen bis-dithiocarbamate are the most used but the variation with farmers of other agricultural areas investigated is the use of specific formulations for a particular plant. This is advancement on farmer's knowledge in this particular area. It may be considered as example of model application commonly used amongst farmers of a given community as discovered by Mohammad et al. [25], within the Sari County (Iran). There is uniformity of using Cypermethrin insecticide. This falls under some of factors mentioned by Selvarajah and Thiruchevam [26] that can influence the behavior of farmers vis-a-vis plant protection. This limitation may be for good of consumers if the amount of residues in foods remains low or a risk if the maximum limit of residues of pesticides is overcome. 
Table 7. Cautions taken by farmers in managing pesticides.

\begin{tabular}{|c|c|c|}
\hline Considerations & Factors & Frequency \\
\hline \multirow{3}{*}{ Area of purchase } & License store & $11(11)$ \\
\hline & Neighborhood & $50(50)$ \\
\hline & Others & $39(39)$ \\
\hline \multirow{4}{*}{ Pest control advice } & Neighbor & $3(3)$ \\
\hline & Pesticide sales agent & $59(59)$ \\
\hline & Relatives & $33(33)$ \\
\hline & Others & $5(5)$ \\
\hline \multirow{6}{*}{ Attire } & Gloves & $7(7)$ \\
\hline & Mask covering nose and mouth & $52(52)$ \\
\hline & Glasses & $22(22)$ \\
\hline & Full sleeved shirts & $10(10)$ \\
\hline & Full shoes & $5(5)$ \\
\hline & None of the above & $4(4)$ \\
\hline \multirow{3}{*}{ Bathing habit } & Not immediately & $46(46)$ \\
\hline & Immediately & $37(37)$ \\
\hline & Do not bath & $17(17)$ \\
\hline \multirow{3}{*}{ Eat and play with kids after use of pesticide } & Yes & $18(18)$ \\
\hline & No & $41(41)$ \\
\hline & Sometimes & $41(41)$ \\
\hline
\end{tabular}

Their knowledge about pesticides related health issues remains ambiguous since some do not even know routes for pesticide penetration in their body. So safety measures will be really poor. This ignorance has led many of them to present symptoms and signs related to the harmfulness of these toxics. Not being conscious of the action of pesticides on their health constitutes an opening for misuse of pesticides. Similar observations were reported from Nepal by Jhalendra et al. [3] among many other authors like Abang et al. [27]. Happening of any intoxication amongst farmers is generally a challenge since the victim is not always transferred to the hospital. Sonchieu et al. [13] remarked that such cases are locally managed by farmers themselves and products generally used are charcoal, liquid milk and palm oil. In most cases, the victim died before reaching the hospital. Pesticides handling remains poor as shown in this study because of the lack of appropriate knowledge on the safe handling and use of pesticides. Abang et al. [27] who found similar information in tropical region of Cameroon attributed this inadequacy to the limited availability of extension services and training.

The management of affected person is very poor because of the above mentioned lack of knowledge. This limitation and ignorance lead some to just 
sweep the affected skin with a piece of cloth while [11] highlighted the dermal route as a major pathway of exposure and were requesting for possible exposure minimization strategies. Nevertheless, this is generally reduced by using personal protective equipment such as goggles, overall cloths, nose and mouth masks which were less used in the area of study [28]. This exposure will directly pose problems of skin irritation, eyes watering, respiratory tract constriction with breathing difficulties and other related symptoms that these farmers ignored about pesticides. In practice, an agricultural operator's exposure to pesticides occurs mainly through the dermal route and to a lesser extent through the inhalation route when he/she does not wear protective clothes or equipment [29]. This result is also backed by a study carried out by Koirala et al. [30] in which they investigated the impact of poor personal hygiene of farmers on the life of family members. EFSA [31] shows that the practice of poor hygiene by farmers will lead to numerous health problems such as respiratory, circulatory and genital problems in the family and the community since pesticides are spread by air and water. This indirect exposure is not to be neglected since the study carried out by Atabila et al. [11] shows a major health risk.

Pesticide residues in food have always mattered in food safety. The ignorance of pesticides to remain inside edible parts of food or in the environment constitute a great deal as far as consumers health is concerned. Farmers will spray and harvest with no consideration about protection of consumers which is the main objective of food regulation. This exposure of the farmers will lead to consumer health risk, with severe consequence as stated by Moon et al. [32], and Karunamoorthi et al. [33] such as depression and neurological deficits. A study carried out by Hanna [1] indicates that the wrong use of pesticides rather causes more harm than good to both the crops and the consumers. This can range from mild, asymptomatic to chronic [22]. Farmers neglect directives given by manufacturers and this creates an avenue for wrong use of these pesticides which will, in turn, be harmful to both the farmer and the consumer if care is not taken as brought out by Karunamoorthi et al. [33]. Also, environmental pollution by these chemicals will be obvious according to studies carried out by many authors such as Hanna [1].

The practice of managing emptied containers is bad since proper directives on how to use, keep and discard waste containers are not respected [20]. Burning, throwing anywhere in the environment, reuse can be considered as contamination pathways. No friendly environmental waste management system recommends such directives. It will lead to the ecosystems' destruction that was observed by Tsozué et al. [16]. This can also be increased through poor storage conditions that will induce degradation of the active ingredients and consequently, increase of impurities and degradation products such as ETU (Ethylene Thio-Urea) which is more toxic than the parent compound [34] [35]. This is commonly observed since pesticides are retailed after reconditioning in small volumes or quantity accessible to small-scale farmers [24]. This is generally done 
with no attire to protect themselves. These poor practices can get explanation on the sense that they are not formally trained and in most cases lack of assistance from the ministry in charge of agriculture and rural development. There is a need for education and training programs for farmers and government employees through community or other forms of IPM programs. Pesticide education programs such as extension training, workshops, and community engagements can be effective in elevating farmers' knowledge on ways to improve pest management practices as in other countries [36]. Assistance of technician would have been for good practices to limit all the lapses reported in this study and preserve health of the entire chain interveners.

\section{Conclusion}

This study was based on ability of farmers from Mount-Bamboutos agricultural area to use pesticides in cropping. It reveals that farmers cropping in this zone have poor knowledge of pesticides use. But the pesticides used are mostly fungicides, of dithiocarbamates class, targeted for some specific crops (vegetables, fruits, roots and tubers). The management of used containers is not environmentally friendly and they may constitute a source of contamination. Factors such as residues in food, health issues, and instructions from manufacturers, routes of contamination and first aids actions when intoxications happened are not well known to the sampled population. The majority do not consider these risk factors when spraying. The place of purchasing, storage and safety measures that they apply remains questionable at the end of this study. The farmers who are globally untrained need assistance of qualified and skilled technicians from the ministry of agriculture and rural development for better protection of consumers and producers.

\section{Acknowledgements}

Authors sincerely thank the local authority of the Ministry of Agriculture and Rural Development (Bamboutos Divisional Delegation) for all facilities that they have been giving to achieve this work.

\section{Conflicts of Interest}

The authors declare that there is no competing interest for this article.

\section{References}

[1] Hanna, A.R. (2018) Pesticide Labels: Protecting Liability or Health?-Unpacking "Misuse" of Pesticides. Current Opinion in Environmental Science \& Health, 4, 10-15. https://doi.org/10.1016/j.coesh.2018.02.004

[2] Matthews, G., Wiles, T. and Baleguel, P. (2003) A Survey of Pesticides Application in Cameroon. Crop Protection, 22, 707-714. https://doi.org/10.1016/S0261-2194(03)00008-5

[3] Jhalendra, P.R., Rajendra, R., Rajan, G., Krishna, D.P., Sudan, G. and Sujata, P. (2018) Farmers' Knowledge on Pesticide Safety and Pest Management Practices: A 
Case Study of Vegetable Growers in Chitwan, Nepal. Agriculture, 8, 16. https://doi.org/10.3390/agriculture8010016

[4] Tinyami, E.T., Choi, J.W., Tumenta, T.S., Eko, A.E. and Chick, O.A. (2014) Small-Scale Tomato Cultivators' Perception on Pesticides Usage and Practices in Buea Cameroon. Health, 6, 2945-2958. https://doi.org/10.4236/health.2014.621333

[5] Yang, P., Iles, M., Yan, S. and Jolliffe, F. (2005) Farmers' Knowledge, Perceptions and Practices in Transgenic Bt Cotton in Small Producer Systems in Northern China. Crop Protection, 24, 229-239. https://doi.org/10.1016/j.cropro.2004.07.012

[6] Colombo, A., Orsi, F. and Bonfanti, P. (2005) Exposure to the Organophosphorus Pesticide Chlorpyrifos Inhibits Acetylcholinesterase Activity and Affects Muscular Integrity in Xenopus laevis Larvae. Chemosphere, 61, 1665-1671. https://doi.org/10.1016/j.chemosphere.2005.04.005

[7] Costa, L.G. (2006) Current Issues in Organophosphate Toxicology. Clinica Chimica Acta, 366, 1-13. https://doi.org/10.1016/j.cca.2005.10.008

[8] Whyatt, R.M., Rauh, V., Barr, D.B., Camann, D.E., Andrews, H.F., Garfinkel, R., Hoepner, L.A., Diaz, D., Dietrich, J., Reyes, A., Tang, D., Kinney, P.L. and Perera, F.P. (2004) Prenatal Insecticide Exposures and Birth Weight and Length among an Urban Minority Cohort. Environmental Health Perspectives, 112, 1125-1132. https://doi.org/10.1289/ehp.6641

[9] Rauh, V.A., Perera, F.P., Horton, M.K., Whyatt, R.M., Bansal, R., Hao, X., Liu, J., Barr, D.B., Slotkin, T.A. and Peterson, B.S. (2012) Brain Anomalies in Children Exposed Prenatally to a Common Organophosphate Pesticide. Proceedings of the $\mathrm{Na}$ tional Academy of Sciences of the USA, 109, 7871-7876.

https://doi.org/10.1073/pnas.1203396109

[10] Atabila, A., Dung, T.P., Jonathan, N.H., Ross, S., Des, C. and Cordia, C. (2018) Health Risk Assessment of Dermal Exposure to Chlorpyrifos among Applicators on Rice Farms in Ghana. Chemosphere, 203, 83-89. https://doi.org/10.1016/j.chemosphere.2018.03.121

[11] Nantia, E.A., David, M.G., Faustin, P.T.M., Sonchieu, J., Paul, F.M., Ana, M.C. and Laura, G.G. (2017) Characterization of Carbamate Pesticides in Natural Water from Cameroon Liquid Chromatography. Analytical Letters, 50, 1397-1409. https://doi.org/10.1080/00032719.2016.1231197

[12] Sonchieu, J., Ngassoum, M.B., Nantia, A.E. and Laxman, P.S. (2017) Pesticide Applications on Some Vegetables Cultivated and Health Implications in Santa, North West-Cameroon. SSRG International Journal of Agriculture \& Environmental Science, 4, 39-46. https://doi.org/10.14445/23942568/IJAES-V4I2P108

[13] Manfo, F.P.T., Moundipa, P.F., Dechaud, H., Tchana, A.N., Nantia, E.A., Zabot, M.T. and Pugeat, M. (2010) Effect of Agro-Pesticides Use on Male Reproductive Function: A Study on Farmers in Djutitsa (Cameroon). Environmental Toxicology, 27, 423-432. https://doi.org/10.1002/tox.20656

[14] WHO (World Health Organisation) (2008) Pesticides: Children's Health and the Environment, WHO Training Package for the Health Sector, World Health Organization. http://www.who.int/ceh

[15] Gountié, D.M., Njonfang, E., Nono, A., Kamgang, P., Zangmo, T.G., Kagou, D.A. and Nkouathio, D.G. (2012) Dynamic and Evolution of the Mounts Bamboutos and Bamenda Calderas by Study of Ignimbritic Deposits (West-Cameroon, Cameroon Line). Syllabus Review, 3, 11-23.

[16] Tsozué, D., Azinwi, P.T. and Ndaka, B.S.M. (2015) Morphology, Physicochemical 
Characteristics and Land Suitability in the Western Highlands of Cameroon. International Journal of Plant \& Soil Science, 7, 29-44. https://doi.org/10.9734/IJPSS/2015/17147

[17] Toh, F.A., Lawrence, M.N., Tsi, E.A. and Mvondo, Z.A. (2018) Impact of Land Use and Land Cover Change on Plant Species Diversity in the Mount Bamboutos Caldera of the Western Highlands of Cameroon. Journal of Biodiversity and Environmental Sciences (JBES), 13, 104-134.

[18] Pouokam, G.B., William, L.A., Alice, S.N. and Mohamed, E.S. (2017) A Pilot Study in Cameroon to Understand Safe Uses of Pesticides in Agriculture, Risk Factors for Farmers' Exposure and Management of Accidental Cases. Toxics, 5, 30. https://doi.org/10.3390/toxics5040030

[19] Tarla, D.N., Tchamba, N.M., Baleguel, N.P., Fontem, D.A., Baleguel, P.D. and Hans, D. (2014) Inventory of Obsolete Pesticide Stockpiles in Cameroon. Scholarly Journal of Agricultural Science, 4, 43-50

[20] Sonchieu, J. (2018) Review on a Probabilistic Exposure of Farmers and Biota to Diuron (Herbicide) Used in Santa, North-West Cameroon. Chemical Science Review and Letters, 6, 88-93.

[21] Sonchieu, J., Fotsing, S.F., Akono, E.N. andNgassoum, M.B. (2018b) Safety Measures and Health Issues among Pesticide Applicators in Foumbot Agricultural Area, West-Region, Cameroon. International Journal of Medical Science and Clinical Invention, 5, 102-110.

[22] Hashemi, M., Rostami, R., Hashemi, M. and Damalas, C.A. (2012) Pesticide Use and Risk Perceptions among Farmers in Southwest Iran. Human Ecological Risk Assessment, 18, 456-470. https://doi.org/10.1080/10807039.2012.652472

[23] Zephania, N.F. (2014) Montane Resources Exploitation and the Emergence of Gender Issues in Santa Economy of the Western Bamboutos Highlands, Cameroon. International Journal of Geography and Régional Planning Research, 1, 1-12.

[24] Matthews, G.A. (2008) Attitudes and Behaviors Regarding Use of Crop Protection Products-A Survey of More than 8500 Smallholders in 26 Countries. Crop Protection, 27, 834-846. https://doi.org/10.1016/j.cropro.2007.10.013

[25] Mohammad, S.S., Gholamhossein, A., Christos, A.D. and Iand, R.R. (2018) Farmers' Criteria for Pesticide Selection and Use in the Pest Control Process. Agriculture, 8, 24-30. https://doi.org/10.3390/agriculture8020024

[26] Selvarajah, A. and Thiruchelvam, S. (2007) Factors Affecting Pesticide Use by Farmers in Vavuniya District. Tropical Agricultural Research, 19, 380-388.

[27] Abang, A.F., Kouame, C.M., Abang, M., Hannah, R. and Fotso, A.K. (2013) Vegetable Growers Perception of Pesticide Use Practices, Cost, and Health Effects in the Tropical Region of Cameroon. International Journal of Agronomy and Plant Production, 4, 873-883.

[28] Hie, L.W., David, G., Garthwaite, C.T.R. and Colin, D.B. (2018) Assessment of Exposure of Professional Agricultural Operators to Pesticides. Science of the Total Environment, 4, 874-882. https://doi.org/10.1016/j.scitotenv.2017.11.127

[29] Yassin, M.M., Mourad, T.A. and Safi, J.M. (2015) Knowledge, Attitude, Practice, and Toxicity Symptoms Associated with Pesticide Use among Farm Workers in the Gaza Strip. Occupational and Environmental Medicine, 59, 387-393. https://doi.org/10.1136/oem.59.6.387

[30] Koirala, P., Tamrakar, A.S., Bhattarai, B.P., Yadav, B.K. and Humagain, S. (2010) Use and Handling Practice of Pesticides in Vegetables: A Case Study on Some Se- 
lected Districts of Nepal. Journal of Food Science and Technology Nepal, 6, 105-109. https://doi.org/10.3126/jfstn.v6i0.8270

[31] EFSA European Food Standard Authority (2014) EFSA Guidance on the Assessment of Exposure for Operators, Workers, Residents and Bystanders in Risk Assessment for Plant Protection Product. EFSA Journal, 12, 3874. https://doi.org/10.2903/j.efsa.2014.3874

[32] Moon, J.K., Park, S., Kim, E., Lee, H. and Kim, J.H. (2013) Risk Assessment of the Exposure of Insecticide Operators to Fenvalerate during Treatment in Apple Orchards. Journal of Agriculture and Food Chemistry, 61, 307-311. https://doi.org/10.1021/jf3043083

[33] Karunamoorthi, K., Mohammed, M. and Wassie, F. (2012) Knowledge and Practices of Farmers with Reference to Pesticide Management: Implications on Human Health. Archives of Environmental Occupational Health, 67, 109-116. https://doi.org/10.1080/19338244.2011.598891

[34] Walash, M.I., Belal, F. and Metwally, M.E. (1993) Hefnawy Spectrophotometric Determination of Maneb, Zineb and Their Decomposition Products in Some Vegetables and Its Application to Kinetic Studies after Greenhouse Treatment. Food Chemistry Analytical Methods Section, 47, 411-416. https://doi.org/10.1016/0308-8146(93)90188-L

[35] CTGB (College voor de toelating van gewasbeschermingsmiddelen en biociden) (2016) Board for the Authorisation of Plant Protection Products and Biocides: Evaluation for the Authorisation of Plant Protection Products and Biocides According to Regulation (EC) No 1107/2009. Chapter 4 Human Toxicology; Mammalian Toxicity Dosser Version 2.1.

[36] Allahyari, M.S., Damalas, C.A. and Ebadattalab, M. (2017) Farmers' Technical Knowledge about Integrated Pest Management (IPM) in Olive Production. Agriculture, 7, 101. https://doi.org/10.3390/agriculture7120101 